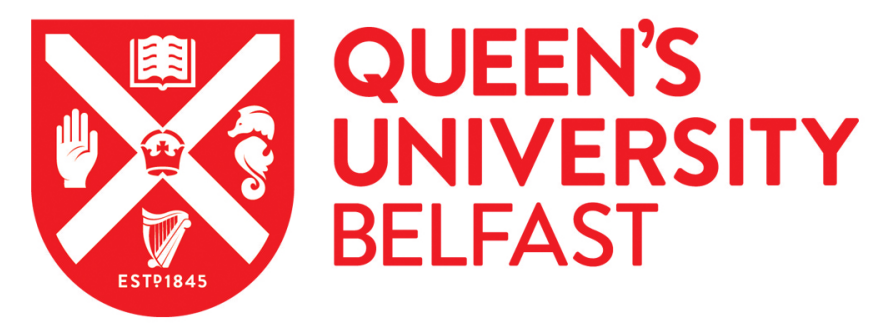

\title{
Face Masks Reduce the Release of Pseudomonas aeruginosa Cough Aerosols when Worn for Clinically-Relevant Time Periods
}

CF Cough Aerosol Group (2018). Face Masks Reduce the Release of Pseudomonas aeruginosa Cough Aerosols when Worn for Clinically-Relevant Time Periods. American Journal of Respiratory and Critical Care Medicine, 198(10), 1339-1342. https://doi.org/10.1164/rccm.201805-0823LE

Published in:

American Journal of Respiratory and Critical Care Medicine

\section{Document Version:}

Peer reviewed version

Queen's University Belfast - Research Portal:

Link to publication record in Queen's University Belfast Research Portal

Publisher rights

(c) 2018 by the American Thoracic Society. This work is made available online in accordance with the publisher's policies. Please refer to any applicable terms of use of the publisher.

\section{General rights}

Copyright for the publications made accessible via the Queen's University Belfast Research Portal is retained by the author(s) and / or other copyright owners and it is a condition of accessing these publications that users recognise and abide by the legal requirements associated with these rights.

Take down policy

The Research Portal is Queen's institutional repository that provides access to Queen's research output. Every effort has been made to ensure that content in the Research Portal does not infringe any person's rights, or applicable UK laws. If you discover content in the Research Portal that you believe breaches copyright or violates any law, please contact openaccess@qub.ac.uk. 
1 Face masks reduce the release of Pseudomonas aeruginosa cough aerosols when worn for

2

3

4

5

7

8

\section{clinically-relevant time periods}

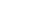

Rebecca E Stockwell ${ }^{1,2}$, Michelle E Wood ${ }^{1,2,3}$, Congrong He ${ }^{4}$, Laura J Sherrard ${ }^{5}$, Emma L

Ballard $^{6}$, Timothy J Kidd ${ }^{1,7}$, Graham R Johnson ${ }^{4}$, Luke D Knibbs ${ }^{8}$, Lidia Morawska ${ }^{4}$, Scott C

Bell*1,2,3; CF Cough Aerosol Group.

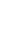

CF cough aerosol group members:

Maureen Peasey, Christine Duplancic, Kay A Ramsay, Nassib Jabbour, Peter O’Rourke,

Claire E Wainwright, Peter D Sly

${ }^{1}$ Lung Bacteria Group, QIMR Berghofer Medical Research Institute, 300 Herston Road, Herston QLD 4006, Australia

${ }^{2}$ Faculty of Medicine, The University of Queensland, Herston QLD 4006, Australia

${ }^{3}$ Adult Cystic Fibrosis Centre, The Prince Charles Hospital, 627 Rode Road, Chermside, QLD 4032, Australia

${ }^{4}$ International Laboratory for Air Quality and Health, Queensland University of Technology, Brisbane QLD 4000, Australia

${ }^{5}$ Queen’s University Belfast, 97 Lisburn Road, Belfast BT9 7BL, United Kingdom

${ }^{6}$ Statistical Support Group, QIMR Berghofer Medical Research Institute, 300 Herston Road, Herston QLD 4006, Australia

${ }^{7}$ School of Chemistry and Molecular Biosciences, The University of Queensland, St Lucia QLD 4067, Australia

${ }^{8}$ School of Public Health, The University of Queensland, Herston QLD 4006, Australia 


\section{Email:}

rebecca.stockwell@qimrberghofer.edu.au

michelle.wood2@health.qld.gov.au

c.he@qut.edu.au

1.sherrard@qub.ac.uk

emma.ballard@qimrberghofer.edu.au

t.m.kidd@uq.edu.au

g.johnson@qut.edu.au

1.knibbs@uq.edu.au

1.morawska@qut.edu.au

scott.bell@qimrberghofer.edu.au

*Corresponding author. Lung Bacteria Group, QIMR Berghofer Medical Research Institute, 300 Herston Road, Herston, Brisbane QLD 4006, Australia.

Tel: +61 73139 4770; Email: scott.bell@qimrberghofer.edu.au

Author contributions: G.R.J., L.D.K., T.J.K., R.E.S., L.J.S., L.M. and S.C.B. conceived and designed the experiment. S.C.B., T.J.K. and L.M. led the funding applications with other members of the CF cough aerosol group (C.E.W and P.D.S.). M.E.W. and S.C.B. recruited the study participants. R.E.S. and C.H. conducted the cough studies. G.R.J. acquired the aerosol data. R.E.S. performed microbiological analysis. E.L.B. led the data analysis. R.E.S. and S.C.B. provide overall responsibility for the data and wrote the manuscript, with input from all co-authors. M.P., C.D., K.A.R., N.J., P.O., C.E.W and P.D.S. provided support to the study including analysis and/or microbiology expertise and/or clinical supervision. 
51 Funding support: The project was funded by Cystic Fibrosis Foundation Therapeutics USA 52 (BELL14AO). T.J.K. acknowledges National Health and Medical Research Council (NHMRC) Early Career (GNT10884488) and ERS-EU RESPIRE2 Marie Sklodowska-Curie Postdoctoral Research (\#4571-2013) Fellowship support. L.D.K. acknowledges an NHMRC Early Career Fellowship (APP1036620). R.E.S acknowledges The Prince Charles Hospital Foundation and Advance Queensland PhD Scholarships.

57

List ONE descriptor number that best classifies the subject of your manuscript: 9.17

Cystic Fibrosis: Translational \& Clinical Studies

60

Total word count for the body of the manuscript $=1328$

61 


\section{Abstract}

Introduction: The cystic fibrosis (CF) infection control guidelines recommend that people with CF wear face-masks when in communal areas of hospitals. Recently, we reported short-term wear of face-masks ( 10-minutes) reduced the release of Pseudomonas aeruginosa aerosols during coughing. However, there is limited evidence to determine if face-masks continue to be effective at reducing the release of infectious cough aerosols after longer wear times. Methods: We recruited 25 people with CF and chronic $P$. aeruginosa infection and 10 healthy volunteers. All participants underwent up to 5 cough tests in a validated cough rig: 1) uncovered cough; 2) coughing with surgical mask worn for 10-minutes; 3) coughing with surgical mask worn for 20-minutes; 4) coughing with a surgical mask worn for 40-minutes; 5) coughing with an N95 respirator worn for 20-minutes (optional). The wear time of the mask included a 5-minute cough period in the aerosol collection rig. Sputum samples and cough aerosols were collected from participants with CF as previously described. All participants rated their level of comfort posttest. Results: Surgical masks and N95 respirators were effective at reducing the release of $P$. aeruginosa aerosols during coughing after 40-minutes total wear and 20-minutes total wear respectively. Both participants with $\mathrm{CF}$ and healthy volunteers rated the surgical masks as more comfortable compared to N95 respirators. Conclusions: Surgical masks were the preferred interface to wear as source control and were effective at reducing the release of $P$. aeruginosa aerosols during coughing after 40-minutes of total wear. 


\section{Introduction}

Aerosol dissemination of respiratory pathogens may contribute to person-to-person transmission in people with cystic fibrosis (CF) [1]. This evolving knowledge of transmission modes has led to an update of the CF Foundation Infection and Prevention Control Guidelines recommending people with $\mathrm{CF}$ wear surgical masks in communal hospital areas to prevent the spread of CF respiratory pathogens [2]. These guidelines recommended the use of surgical masks as source control despite limited evidence for this application.

We recently demonstrated that short-term wear of face-masks (10-minutes total wear) significantly reduces the release of Pseudomonas aeruginosa aerosols during coughing in people with CF [3]. These findings are consistent with an earlier study of people with CF that reached the same conclusion after very short-term wear of surgical masks (worn for 21 coughs) [4]. These results and a recent editorial to our short-term mask wear study [5] support our current aim to investigate the effectiveness, tolerability and functionality of face-masks as source control after extended wear.

\section{Methods}

We recruited 25 people with $\mathrm{CF}$ and chronic P. aeruginosa infection [6] from the Adult Cystic Fibrosis Centre, The Prince Charles Hospital, Brisbane, Australia. Ten healthy volunteers were recruited from hospital and research staff to assess mask comfort and mask weight change. All participants performed up to five randomly ordered tests in a validated cough system [7]: 1) uncovered cough; 2) coughing with surgical mask worn for 10-minutes); 3) coughing with surgical mask worn for 20-minutes; 4) coughing with surgical mask worn for 40-minutes; 5) coughing with N95 mask worn for 20-minutes [3, 7]. The N95 test was an optional test based on the poor comfort ratings observed in our earlier mask study [3]. 
The duration of the mask wear tests were selected based on observation of patients moving around communal areas of the hospital described here. Two types of masks were tested: “surgical mask" [Catalogue \# 47107; Halyard FLUIDSHIELD Level 3 Fog-Free Procedure Mask $(\Delta \mathrm{P}<2.5)$, Georgia, USA] and "N95 mask" [Catalogue \# 46827 (small) or 46727 (regular), Halyard FLUIDSHIELD N95 Particulate Filter Respirator and Surgical Mask, Georgia, USA]. New masks were used for each test. The total wear time of the masks included 1-minute positioning of the participant into the rig, 2-minutes of tidal breathing with HEPAfiltered air, a 5-minute cough period, followed by another 2-minutes of tidal breathing. Cough aerosol collection, sputum processing and P. aeruginosa genotyping were performed as previously described $[1,3,8]$. All participants rated their comfort levels after each test $[3,9]$. All masks were weighed before and following each test.

SPSS version 25 was used for statistical analysis. Participants with CF were stratified by the amount of aerosol colony forming units (CFU) produced during the uncovered cough test: high producer (total CFU was $\geq 10$ ) or no/low producer (total CFU was $<10$ ) [3]. Categorical variables were examined using Pearson Chi-squared test or Fisher's Exact test. Continuous variables were examined using a Student t-test or Mann-Whitney U test. CFU were $\log$ transformed and the paired t-test examined changes over time. The McNemar-Bowker test was used to examine comfort scores over time. The Wilcoxon Signed Rank Test was used to examine the change in mask weight over time.

\section{Results}

P. aeruginosa was cultured from the sputum of $25 / 25$ participants with $\mathrm{CF}$ and was cultured in cough aerosols during the uncovered cough test of 20/25 participants (Table 1). P. aeruginosa 
was cultured from cough aerosols of 9/20 participants during any of the surgical mask tests (10minutes, 20-minutes and 40-minutes total wear time) and 4/20 participants during the N95 mask test of 20-minutes total wear. The CFU were significantly reduced for the surgical mask tests compared with the uncovered cough test $(\mathrm{p}<0.001)$. Between mask tests, the CFU count remained similar as the duration of surgical mask wear increased as well as between mask types (Table 1). The $P$. aeruginosa strain types found in the cough aerosols were genetically indistinguishable from the paired sputum sample of each participant.

Participants with CF rated surgical masks less comfortable than healthy volunteers for all test durations (surgical mask: 10-minutes, $\mathrm{p}=0.001 ; 20$-minutes, $\mathrm{p}=0.007 ; 40$-minutes, $\mathrm{p}=0.023$; N95: 20-minutes, $p=0.018$ ) (Table 2). Participants with CF were more tolerant of surgical mask wear (good comfort) after 10- and 20-minutes total wear time if they had higher lung function, yet this difference was lost after 40-minutes of surgical mask wear. N95 masks were rated less comfortable in both participants with CF and healthy volunteers (Table 2).

The change in mask weight for each test ranged from no weight change to a maximum weight change of $0.02 \mathrm{~g}$ and was comparable between participants with $\mathrm{CF}$ and healthy volunteers (Table 2). There was a minor increase in surgical mask weight (median change, $0.01 \mathrm{~g}$ ) after 40minutes compared with 10-minutes wear $(p=0.031)$ (Table 2). No statistical differences in mask weight change were seen in other time or mask type comparisons (Table 2).

\section{Discussion}

Our study demonstrates that face masks worn for clinically-relevant time periods are effective at reducing the release of potentially infectious aerosols during coughing in people with CF. These results extend upon our earlier observations that demonstrated surgical masks and N95 
masks were both effective at reducing the release of infectious cough aerosols when the mask wear was of shorter duration [3]. The outcomes of our studies demonstrate that surgical masks are effective and tolerable as source control [3] and support the CF Foundation (USA) recommendations for surgical mask wear to reduce the risk of CF pathogen transmission in the hospital setting [2].

Surgical masks were the preferred mask type for source control in terms of comfort, which is similar to our short-term wear mask study findings [3]. Healthy volunteers tolerated the surgical masks better than those with $\mathrm{CF}$ and participants with $\mathrm{CF}$ who had higher lung function tolerated surgical masks better. When the comfort of surgical masks was assessed after extended wear in this cohort, a major finding was that the comfort ratings remained unchanged regardless of wear time for both people with and without CF. Therefore, surgical masks are not only effective but are also well tolerated by participants after 40 -minutes total wear.

An accompanying editorial of our recent mask study [3] questioned if mask dampness may affect the ability of the mask to function as source control after prolonged wear times [5]. The $\mathrm{CF}$ infection control guidelines indicate that masks being used as source control should be replaced when damp [2] and excessive moisture accumulation was a common reason for surgical mask replacement in people with tuberculosis using surgical masks as source control [10]. Our data indicates that although there was evidence of surgical mask moisture accumulation after 40-minutes total wear (estimated by increased weight), the surgical mask continued to function effectively as source control mitigating this concern.

There are several limitations to this study: 1) The infectious dose of $P$. aeruginosa is unknown and therefore the infection risk cannot be determined; 2) Participants remained in view of staff 
while wearing the masks and this may have modified the extent to which participants interfered with the mask leading to an incorrect estimation on the masks protective effects; 3) Participants were seated during the cough testing and this may have impacted on the participant's ability to cough freely; 4) While some participants experienced episodes of spontaneous cough during testing, we were unable to differentiate between spontaneous and voluntary cough. Therefore, the protective effects of the masks may be overestimated; 5) The effectiveness and tolerability of masks is reported in adults only and these characteristics need to be studied in children; 6) Our study had a maximum wear time of 40-minutes and the effectiveness of masks worn for longer periods is unknown; 7) We did not assess inward protection provided by masks but this has been highlighted as an understudied field of research [11].

Our study confirms the effectiveness of surgical masks at reducing the release of $P$. aeruginosa cough aerosols in people with $\mathrm{CF}$ and provides evidence of patient tolerability and functionality of these masks as source control after 40-minutes of total wear.

Acknowledgements: We thank Dr Farhad Salimi for his aerosol support to the study. We thank Greg Flohr and staff from the Central Pathology Laboratory (Royal Brisbane and Women's Hospital), Pathology Queensland for microbiological support to the study. We thank the Adult CF Centre team in supporting recruitment to the studies. We also thank all the participants in the study for supporting the work. 


\begin{tabular}{|c|c|c|c|c|c|c|}
\hline & \multicolumn{3}{|c|}{ Group } & \multicolumn{3}{|c|}{ Production level in CF participants } \\
\hline & $\begin{array}{l}\text { Healthy } \\
(\mathrm{n}=10)\end{array}$ & $\begin{array}{c}C F \\
(n=25)\end{array}$ & p-value & $\begin{array}{c}\text { No/low } \\
(<10 \mathrm{CFU}) \\
(\mathbf{n}=\mathbf{1 4})\end{array}$ & $\begin{array}{c}\text { High } \\
(\geq 10 \mathrm{CFU}) \\
(\mathbf{n}=\mathbf{1 1})\end{array}$ & p-value \\
\hline Participant characteristics & & & & & & \\
\hline Age, years, mean (SD) & $37.3(12.3)$ & $33.3(9.0)$ & 0.29 & $36.7(9.3)$ & $28.9(6.9)$ & 0.029 \\
\hline Sex, male, n (\%) & $6(60.0)$ & $15(60.0)$ & 1.00 & $9(64.3)$ & $6(54.5)$ & 0.70 \\
\hline Body mass index $(\mathrm{BMI}), \mathrm{kg} / \mathrm{m}^{2}$, mean $(\mathrm{SD})$ & $24.6(3.5)$ & $22.8(3.2)$ & 0.14 & $22.5(3.7)$ & $23.1(2.6)$ & 0.63 \\
\hline $\mathrm{FEV}_{1} \%$ predicted, mean $(\mathrm{SD})$ & $92.6(9.2)$ & $53.8(20.8)$ & $<0.001$ & $54.2(23.2)$ & $53.3(18.2)$ & 0.91 \\
\hline Mean P. aeruginosa sputum concentration, x $10^{7} \mathrm{CFU} / \mathrm{mL}(95 \% \mathrm{CI})^{\mathrm{a}}$ & $\mathrm{n} / \mathrm{a}$ & $\begin{array}{c}5.2(2.1- \\
12.9)\end{array}$ & - & $1.9(0.7-5.7)$ & $18.3(4.7-70.9)$ & 0.008 \\
\hline Participants with $P$. aeruginosa detected in cough aerosols & & & & & & \\
\hline $\begin{array}{l}\text { Uncovered cough test } \\
\qquad \begin{array}{l}\mathrm{n}(\%) \\
\text { Mean CFU }(95 \% \mathrm{CI})^{\mathrm{a}}\end{array}\end{array}$ & $\mathrm{n} / \mathrm{a}$ & $\begin{array}{c}20(80.0) \\
17(7-43)\end{array}$ & - & $\begin{array}{l}9(64.3) \\
2(1-4)\end{array}$ & $\begin{array}{c}11(100.0) \\
75(34-165)\end{array}$ & $<0.001^{\mathrm{d}}$ \\
\hline $\begin{array}{l}\text { Surgical mask tests } \\
\begin{array}{l}\text { 10-minutes total wear } \\
\mathrm{n}(\%) \\
\text { Mean CFU }(95 \% \mathrm{CI})^{\mathrm{a}}\end{array}\end{array}$ & $\mathrm{n} / \mathrm{a}$ & $\begin{array}{c}9(36.0) \\
4(1-10)\end{array}$ & - & $\begin{array}{c}1(7.1) \\
1\end{array}$ & $\begin{array}{c}8(72.7) \\
5(1-13)\end{array}$ & \\
\hline $\begin{array}{l}\text { 20-minutes total wear } \\
\text { n }(\%) \\
\text { Mean CFU }(95 \% \mathrm{CI})^{\mathrm{a}}\end{array}$ & $\mathrm{n} / \mathrm{a}$ & $\begin{array}{c}9(36.0) \\
4(1-10)\end{array}$ & - & $\begin{array}{c}1(7.1) \\
1\end{array}$ & $\begin{array}{c}8(72.7) \\
4(1-11)\end{array}$ & $0.99^{\mathrm{e}}$ \\
\hline $\begin{array}{l}\text { 40-minutes total wear } \\
\mathrm{n}(\%) \\
\text { Mean CFU }(95 \% \mathrm{CI})^{\mathrm{a}}\end{array}$ & $\mathrm{n} / \mathrm{a}$ & $\begin{array}{l}9(36.0) \\
3(1-7)\end{array}$ & - & $\begin{array}{c}1(7.1) \\
1\end{array}$ & $\begin{array}{l}8(72.7) \\
4(1-9)\end{array}$ & $0.56^{\mathrm{f}}, 0.64^{\mathrm{g}}$ \\
\hline $\begin{array}{l}\text { N95 mask test } \\
\text { 20-minutes total wear }(\mathrm{n}=23) \\
\text { n }(\%) \\
\text { Mean CFU }(95 \% \mathrm{CI})^{\mathrm{a}}\end{array}$ & $\mathrm{n} / \mathrm{a}$ & $\begin{array}{l}4(17.4) \\
2(0-6)\end{array}$ & - & $\begin{array}{c}0(0.0)^{\mathrm{b}} \\
\mathrm{n} / \mathrm{a}\end{array}$ & $\begin{array}{l}4(40.0)^{\mathrm{c}} \\
2(0-6)\end{array}$ & $0.19^{\mathrm{h}}$ \\
\hline
\end{tabular}


Definitions: $\mathrm{FEV}_{1}$, forced expiratory volume in 1 second; CFU, colony forming unit; $\mathrm{CFU} / \mathrm{mL}$, CFU per millilitre of sputum; SD, standard deviation; CI, confidence interval, $\mathrm{n} / \mathrm{a}$, not applicable $\sim$ Optional test
${ }^{\mathrm{d} U n c o v e r e d ~ c o u g h ~(g e o m e t r i c ~ m e a n ~ C F U) ~ c o m p a r e d ~ t o ~ e a c h ~ s u r g i c a l ~ m a s k ~ t e s t ~(g e o m e t r i c ~ m e a n ~ C F U) ~}$
eSurgical masks (geometric mean CFU): 10-minutes versus 20-minutes total wear
fSurgical masks (geometric mean CFU): 10-minutes versus 40-minutes total wear
'Surgical masks (geometric mean CFU): 20-minutes versus 40-minutes total wear
213 hean CFU surgical mask 20-minutes total wear versus mean CFU N95 mask 20-minutes total wear 


\begin{tabular}{|c|c|c|c|c|c|}
\hline \multirow[b]{2}{*}{ Mask properties } & \multicolumn{3}{|c|}{ Mask comfort } & \multicolumn{2}{|c|}{ Mask weight change } \\
\hline & $\begin{array}{c}\text { Healthy } \\
\text { n (\%) }\end{array}$ & $\begin{array}{c}\text { CF } \\
\text { n (\%) }\end{array}$ & p-value & $\begin{array}{l}\text { All participants } \\
\text { Median (IQR) }\end{array}$ & p-value \\
\hline Uncovered cough comfort level & & & 1.00 & $\mathrm{n} / \mathrm{a}$ & $\mathrm{n} / \mathrm{a}$ \\
\hline Poor & $0(0.0 \%)$ & $0(0.0 \%)$ & & & \\
\hline Sufficient & $1(10.0 \%)$ & $2(8.0 \%)$ & & & \\
\hline Good & $9(90.0 \%)$ & $23(92.0 \%)$ & & & \\
\hline Coughing wearing a surgical mask -10 -minutes total wear & & & 0.001 & $0.01 \mathrm{~g}(0.00 \mathrm{~g}-0.02 \mathrm{~g})$ & $\mathrm{n} / \mathrm{a}$ \\
\hline Poor & $1(10.0 \%)$ & $0(0.0 \%)$ & & & \\
\hline Sufficient & $0(0.0 \%)$ & $15(60.0 \%)$ & & & \\
\hline Good & $9(90.0 \%)$ & $10(40.0 \%)$ & & & \\
\hline Coughing wearing a surgical mask -20 -minutes total wear & & & 0.007 & $0.01 \mathrm{~g}(0.00 \mathrm{~g}-0.02 \mathrm{~g})$ & $0.73^{\mathrm{a}}$ \\
\hline Poor & $1(10.0 \%)$ & $1(4.0 \%)$ & & & \\
\hline Sufficient & $0(0.0 \%)$ & $13(52.0 \%)$ & & & \\
\hline Good & $9(90.0 \%)$ & $11(44.0 \%)$ & & & \\
\hline Coughing wearing a surgical mask -40 -minutes total wear & & & 0.023 & $0.02 \mathrm{~g}(0.01 \mathrm{~g}-0.03 \mathrm{~g})$ & $0.25^{\mathrm{b}}, 0.031^{\mathrm{c}}$ \\
\hline Poor & $1(10.0 \%)$ & $2(8.0 \%)$ & & & \\
\hline Sufficient & $1(10.0 \%)$ & $15(60.0 \%)$ & & & \\
\hline Good & $8(80.0 \%)$ & $8(32.0 \%)$ & & & \\
\hline Coughing wearing N95 mask -20-minutes total wear & & & 0.018 & $0.02 \mathrm{~g}(0.00 \mathrm{~g}-0.04 \mathrm{~g})$ & $0.21^{\mathrm{d}}$ \\
\hline Poor & $0(0.0 \%)$ & $11(47.8 \%)$ & & & \\
\hline Sufficient & $7(77.8 \%)$ & $8(34.8 \%)$ & & & \\
\hline Good & $2(22.2 \%)$ & $4(17.4 \%)$ & & & \\
\hline
\end{tabular}

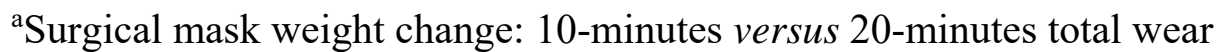
burgical mask weight change: 20 -minutes versus 40-minutes total wear 'Surgical mask weight change: 10-minutes versus 40-minutes total wear

219 dMask weight change after 20-minutes wear: surgical mask versus N95 mask 


\section{References:}

1. Knibbs, L.D., Johnson, G.R., Kidd, T.J., Cheney, J., Grimwood, K., Kattenbelt, J.A., O'Rourke, P.K., Ramsay, K.A., Sly, P.D., Wainwright, C.E., Wood, M.E., Morawska, L., and Bell, S.C. Viability of Pseudomonas aeruginosa in cough aerosols generated by persons with cystic fibrosis. Thorax. 2014;69(8):740-5

2. Saiman, L., Siegel, J.D., LiPuma, J.J., Brown, R.F., Bryson, E.A., Chambers, M.J., Downer, V.S., Fliege, J., Hazle, L.A., Jain, M., Marshall, B.C., O'Malley, C., Pattee, S.R., Potter-Bynoe, G., Reid, S., Robinson, K.A., Sabadosa, K.A., Schmidt, H.J., Tullis, E., Webber, J., and Weber, D.J. Infection prevention and control guideline for cystic fibrosis: 2013 update. Infect Control Hosp Epidemiol. 2014;35 Suppl 1:S1-s67

3. Wood, M.E., Stockwell, R.E., Johnson, G.R., Ramsay, K.A., Sherrard, L.J., Jabbour, N., Ballard, E., O'Rourke, P., Kidd, T.J., Wainwright, C.E., Knibbs, L.D., Sly, P.D., Morawska, L., and Bell, S.C. Face Masks and Cough Etiquette Reduce the Cough Aerosol Concentration of Pseudomonas aeruginosa in People with Cystic Fibrosis. Am J Respir Crit Care Med. 2018;197(3):348-355

4. Driessche, K.V., Hens, N., Tilley, P., Quon, B.S., Chilvers, M.A., de Groot, R., Cotton, M.F., Marais, B.J., Speert, D.P., and Zlosnik, J.E. Surgical masks reduce airborne spread of Pseudomonas aeruginosa in colonized patients with cystic fibrosis. Am J Respir Crit Care Med. 2015;192(7):897-9

5. Simmonds, N.J. and Bush, A. The Man in the Paper Mask: One (Mask) for All and All for . . . Cystic Fibrosis? Am J Respir Crit Care Med. 2018;197(3):281-283

6. Ramsay, K.A., Sandhu, H., Geake, J.B., Ballard, E., O'Rourke, P., Wainwright, C.E., Reid, D.W., Kidd, T.J., and Bell, S.C. The changing prevalence of pulmonary infection in adults with cystic fibrosis: A longitudinal analysis. J Cyst Fibros. 2017;16(1):70-77 
7. Johnson, G.R., Knibbs, L.D., Kidd, T.J., Wainwright, C.E., Wood, M.E., Ramsay, K.A., Bell, S.C., and Morawska, L. A Novel Method and Its Application to Measuring Pathogen Decay in Bioaerosols from Patients with Respiratory Disease. PLoS One. 2016;11(7):e0158763

8. Syrmis, M.W., Kidd, T.J., Moser, R.J., Ramsay, K.A., Gibson, K.M., Anuj, S., Bell, S.C., Wainwright, C.E., Grimwood, K., Nissen, M., Sloots, T.P., and Whiley, D.M. A comparison of two informative SNP-based strategies for typing Pseudomonas aeruginosa isolates from patients with cystic fibrosis. BMC Infect Dis. 2014;14:307

9. Gregoretti, C., Confalonieri, M., Navalesi, P., Squadrone, V., Frigerio, P., Beltrame, F., Carbone, G., Conti, G., Gamna, F., Nava, S., Calderini, E., Skrobik, Y., and Antonelli, M. Evaluation of patient skin breakdown and comfort with a new face mask for noninvasive ventilation: a multi-center study. Intensive Care Med. 2002;28(3):278-84

10. Dharmadhikari, A.S., Mphahlele, M., Stoltz, A., Venter, K., Mathebula, R., Masotla, T., Lubbe, W., Pagano, M., First, M., Jensen, P.A., van der Walt, M., and Nardell, E.A. Surgical face masks worn by patients with multidrug-resistant tuberculosis: impact on infectivity of air on a hospital ward. Am J Respir Crit Care Med. 2012;185(10):1104-9

11. MacIntyre, C.R., and Chughtai, A.A. Facemasks for the prevention of infection in healthcare and community settings. BMJ. 2015;350:h694 